\title{
Peering Through the Smoke: The Effect of Parental Smoking Behavior and Addiction on Daily Smokers' Attentional Bias to Smoking Cues
}

Cheryl L. Dickter

William \& Mary, cldickter@wm.edu

Catherine A. Forestell

William \& Mary, caforestell@wm.edu

Follow this and additional works at: https://scholarworks.wm.edu/aspubs

Part of the Health Psychology Commons

\section{Recommended Citation}

Dickter, Cheryl L. and Forestell, Catherine A., Peering Through the Smoke: The Effect of Parental Smoking Behavior and Addiction on Daily Smokers' Attentional Bias to Smoking Cues (2012). Addictive Behaviors, 37(2), 187-192.

https://doi.org/10.1016/j.addbeh.2011.09.017

This Article is brought to you for free and open access by the Arts and Sciences at W\&M ScholarWorks. It has been accepted for inclusion in Arts \& Sciences Articles by an authorized administrator of W\&M ScholarWorks. For more information, please contact scholarworks@wm.edu. 


\section{Addictive Behaviors}

\section{Highlights}

Peering through the smoke: The effect of parental smoking behavior and addiction on daily smokers' attentional bias to smoking cues

Cheryl L. Dickter *, Catherine A. Forestell

The College of William and Mary

- Implicit attentional biases to smoking and control cues were measured in smokers. Daily smokers with a smoking parent showed a bias to inactive smoking cues. $>$ Occasional smokers did not show a bias regardless of whether their parents smoked. $\triangleright$ Daily smokers' bias to inactive cues was also influenced by nicotine dependence. 


\title{
Peering through the smoke: The effect of parental smoking behavior and addiction on daily smokers' attentional bias to smoking cues
}

\author{
Cheryl L. Dickter ${ }_{\Lambda}^{*}$, ${ }_{\Lambda}$ Catherine A. Forestell \\ The College of William and Mary
}

\section{A R T I C L E I N F O}

Available online xxxx

\section{Keywords:}

Daily smokers

Attentional bias

Addiction

Parental smoking

Dot-probe

\begin{abstract}
A B S T R A C T
Although previous research has demonstrated that individuals with parents who smoke are more likely to 18 become smokers and are less successful in smoking cessation efforts compared with those without a smoking 19 parent, the reasons for this link have not been established. In the current study, implicit attentional bias to 20 smoking-related cues was investigated in college-age smokers, based on models of addiction that suggest 21 that attention to drug-related cues plays an important role in drug addiction. Sixty-one participants complet- 22 ed a dot-probe task to measure attentional bias to smoking-related and matched non-smoking-related con- 23 trol pictures. Results indicated that while those who reported smoking occasionally did not demonstrate an 24 attentional bias, daily smokers who had a smoking parent showed more of an attentional bias to the smoking 25 cues than those without a smoking parent, but only to cues that did not contain human content. In addition to 26 parental influence, nicotine dependence explained a significant portion of the variance in the attentional bias 27 for daily smokers. Implications for models of nicotine addiction and the development of smoking cessation 28 programs are discussed.

(C) 2011 Published by Elsevier Ltd. 30
Smoking is the leading cause of preventable death in the United States, claiming over 440,000 lives each year (American Cancer Society, 2009; Rivara et al., 2004). In addition to the negative health impact on those who smoke cigarettes, research has shown that children who live with a parent who smokes also suffer from a variety of adverse health effects (European Environment and Health Information System [ENHIS], 2007). Moreover, they are two to three times more likely to experiment with smoking and become habitual smokers for a greater number of years (Bauman, Foshee, Linzer, \& Koch, 1990; Chassin, Presson, Rose, Sherman, \& Prost, 2002; Den Exter Blokland, Engels, Hale, Meeus, \& Willemsen, 2004), have more difficulty quitting, and are at increased risk for relapse during quit attempts (Kleinjan et al., 2009) than children without a family history of smoking. Although research has established a link between smoking behavior in parents and their offspring, the reasons for this link remain unclear.

One factor that may mediate this relationship is the existence of an attentional bias for smoking-related cues in those who have smoking parents. This notion has been supported by recent work by Forestell-et at. (in press) which demonstrated that parental smoking is associated with an attentional bias to smoking-related cues in non-smokers. Attentional biases are thought to be implicit (McCusker, 2001), and can lead to increases in the detection of drug-related stimuli in the environment and drug-related cognitions, and a reduction in the amount of cognitive resources available for other tasks (Franken, 2003), all of which can lead

* Corresponding author at: Department of Psychology, College of William and Mary, PO Box 8795, Williamsburg, VA 23187-8795. Tel.: +1 7572213722.

E-mail address: cldickter@wm.edu (C.L. Dickter). smokers to maintain smoking behavior and fail in their quit attempts 59 (Waters et al., 2003; Williams, Mathews, \& MacLeod, 1996). This may 60 help to explain why children of smokers initiate smoking earlier (Chassin, 61 Presson, Pitts, \& Sherman, 2000; Den Exter Blokland et al., 2004), smoke 62 more frequently (Flay et al., 1994), and have more difficulty quitting 63 (Kleinjan et al., 2009) than those without a family history of smoking. 64 This contention is further supported by theories of drug addiction 65 which have shown that attention to drug-related cues plays an important 66 role in the maintenance of drug addiction (e.g., Robinson \& Berridge, 67 1993). That is, smokers have been shown to orient faster toward, main- 68 tain their gaze upon, and exhibit greater neural activation in response 69 to smoking-related versus neutral stimuli compared to non-smokers 70 (Bradley, Mogg, Wright, \& Field, 2003; Littel \& Franken, 2007; Mogg, 71 Q3 Bradley, Field, \& De Houwer, 2003; Warren \& McDonough, 1999). How- 72 Q4 ever, to our knowledge, previous research has not examined whether pa- 73 rental smoking leads to an attentional bias in smokers.

College smokers are a particularly interesting group in which to 75 evaluate attentional bias to smoking-related stimuli as 40\% report 76 that they smoke (Stromberg, Nichter, \& Nichter, 2007), with a sizable 77 proportion of individuals increasing their smoking behavior during 78 these years (e.g., Chassin, Presson, Sherman, \& Pitts, 2000; Chassin, 79 Sherman, Presson, \& Edwards, 1991). In fact, college students are 80 the only group for which smoking prevalence has remained stable 81 in the United States, while most other groups have shown declines 82 in smoking rates (Centers for Disease Control and Prevention (CDC), 83 2009). College smokers demonstrate considerable individual variabil- 84 ity in their smoking frequency (Colder et al., 2006). Approximately 85 $40-50 \%$ are daily smokers who smoke at least one cigarette every 86 
day and exhibit physiological and psychological withdrawal symptoms when deprived of cigarettes for a prolonged period of time; the remaining are occasional smokers (Moran, Wechsler, \& Rigotti, 2004; Otsuki, Tinsley, Chao, \& Unger, 2008). These groups tend to differ in their motivations for smoking (Otsuki et al., 2008; Stromberg et al., 2007) as well as their affective reactivity to smoking cues. That is, daily smokers show more positive implicit responses to smoking-related cues than control cues, while occasional smokers show no differences in their responses to these two types of stimuli (Haight \&ickter, submitted for publication). Other studies have also demonstrated that college students who smoke on a daily basis respond more negatively to smoking-related pictures than those who smoke less frequently (Sherman, Rose, Koch, Presson, \& Chassin, 2003, Study 2), suggesting that implicit reactions to smoking cues may vary as a function of smoking frequency.

The primary goal of the current study was to investigate whether parental smoking behavior interacts with smoking patterns (i.e., daily vs. occasional smoking) to predict attentional bias to smoking-related stimuli. To this end, a dot-probe paradigm that presented smokingrelated and non-smoking-related control pictures was used, based on its demonstrated ability to measure implicit drug-related attentional biases (Bradley et al., 2003; Forestell et al., in press). Based on our previous findings with non-smokers (Forestell et al., in press), we predicted that daily and occasional smokers with smoking parents would show an attentional bias to smoking-related cues. However, it was expected that daily smokers would additionally demonstrate an attentional bias for smoking-related cues as a function of their dependence on nicotine (Bradley, Field, Mogg, \& Houwer, 2004). We predicted that this additive effect of parental smoking and dependence on nicotine would not occur in occasional smokers because they are typically motivated by environmental cues such as social situations and interactions with smoking peers (Otsuki et al., 2008; Stromberg et al., 2007), rather than the physiological effects of nicotine.

This study utilized two different types of smoking and matched control stimuli in the dot-probe paradigm: those that depict the smoking and control stimuli alone (inactive) and those that depict a human interacting with the cues (active). This manipulation addresses an identified limitation in the field as previous studies have not controlled for the human content presented in stimulus pictures. This is problematic because it is not clear whether variation in the stimuli contributed to the variability in participants' implicit responses (Stritzke, Breiner, Curtin, \& Lang, 2004). For example, because human-related stimuli yield greater early cognitive processing than pictures of objects alone (e.g., Bentin, Allison, Puce, Perez, \& McCarthy, 1996), participants may focus primarily on the human components of the active pictures, distracting them from the smoking-related stimuli. Indeed, previous research from our laboratory that manipulated the human content within the stimulus pictures found that family smoking was related to attentional bias only to inactive smoking-related pictures (Forestell et al., ondary goal of the present paper was to determine whether participants' attentional bias to smoking-related cues was moderated by whether the picture cues contained a human. Based on our previous research with non-smokers (Forestell et al., in press), we hypothesized that daily smokers with a family history of smoking would demonstrate a stronger attentional bias to inactive smoking-related cues than daily smokers without a family history of smoking, while no effects were expected for active pictures.

\section{Method}

\subsection{Participants}

Seventy (40 male) smoking undergraduates at a medium-sized liberal arts college were recruited through an online database and provided with credit in their introductory psychology course or recruited through advertisements and paid $\$ 10$ for their participation. Most of the participants were White $(n=50)$, with the remaining individuals of color (1 Black, 3 Asian, 12 mixed, 2 "other," and 2150 non-responses). Participants had an average age of 19.83 years 151 $(S D=3.46)$. All procedures were approved by the school's Protection 152 of Human Subjects Committee, and written informed consent was 153 obtained from each participant.

\section{Materials}

\subsection{Stimuli}

The experimental stimuli consisted of 120 color photographs which 157 included 60 smoking-related stimuli. ${ }^{1}$ Half of the pictures were active in 158 that they depicted a person interacting with the stimulus, whereas the 159 remaining pictures were inactive, in that they consisted of the stimulus 160 alone. These pictures were presented in pairs that included a smoking- 161 related image as well as a matched neutral image. The sixty neutral pho- 162 tographs were created to be similar on various visual properties such as 163 color, brightness, and object position. All images were successfully 164 pilot-tested with 10 non-smoking undergraduates to ensure that partic- 165 ipants could identify their contents and judge whether or not they were 166 drug-related. The average accuracy rate for smoking and non-smoking- 167 related stimuli was $98 \% \pm 0.08$ (Range: $90 \%-100 \%$ ).

\subsection{Questionnaires}

In addition to demographic questions about participants' age, ethnic 170 and racial background, family income and parents' level of education, a 171 set of general smoking-related questions were included to measure age 172 at consumption of first cigarette, their current daily smoking habits, and 173 their parents' smoking behaviors. A family history questionnaire deter- 174 mined how many of the participants' first degree relatives (i.e., mother, 175 father, siblings) smoke cigarettes and the amount of time they spent 176 with these smokers currently and in the past. Because of the high co- 177 morbidity between smoking and drinking (Saules et al., 2004), partici- 178 pants were interviewed to determine the frequency of drinking, 179 amount of alcohol consumed on a single occasion, type of alcoholic bev- 180 erages consumed (i.e., beer, wine, liquor) and size of beverage using a 181 time-line follow-back questionnaire. From these data, we estimated 182 the number of standard drinks of alcohol consumed during the previous 183 three weeks (Mennella \& Forestell, 2008).

The Fagerström Test of Nicotine Dependence (FTND; Heatherton, 185 Q10 Kozlowski, Frecker, \& Fagerström, 1991) was included to measure 186 smokers' dependence upon nicotine. This brief questionnaire consists 187 of the following six items: time to the first cigarette of the day, level of 188 difficulty refraining from smoking, importance of the first morning 189 cigarette, smoking frequency, importance of smoking in the morning, 190 and determination to smoke. Scores range from 0 to 10, with higher 191 scores indicating a greater level of dependence. Reliability of this 192 questionnaire is .78, and Cronbach alpha levels for internal consisten- 193 cy range from 0.56 - 0.70 (Etter, Duc, \& Perneger, 1999; Haddock, 194 Lando, Klesges, Talcott, \& Renaud, 1999; Payne, Smith, McCracken, 195 McSherry, \& Antony, 1994; Pomerleau, Carton, Lutzke, Flessland, \& 196 Pomerleau, 1994).

\subsection{Computer Task}

198

All participants completed a dot-probe task to measure their at- 199 tentional bias. The task consisted of two blocks counterbalanced 200 across participants. Each contained 60 trials, for a total of 120 trials. 201 Each trial began when a fixation-cross appeared in the middle of the 202

\footnotetext{
1 The remaining photographs consisted of 60 alcohol-related and matched non-alcohol-related control pictures. However, only reaction times to smoking and non-smoking-related target stimuli (i.e. those replaced by a probe in the dot-probe task) are analyzed since the theoretical and analytical focus of the present study is reactions to smoking-related stimuli by smokers.
} 
computer screen for 1000 milliseconds (ms). A picture pair then appeared on the screen for either 500 or $2000 \mathrm{~ms}$, on either side of where the fixation-cross had been, depending on the block. Each pair was presented with equal probability in random order. Different presentation times were used because previous research demonstrated that attentional bias to smoking-related relative to non-smokingrelated cues differed based on the stimulus presentation time (Bradley et al., 2003) as a function of smoking exposure. Visual masks then replaced the images for $433 \mathrm{~ms}$. Following the masks, a black dot appeared where one of the pictures had previously been. The participants' task was to identify the side of the screen (i.e., left or right) on which the dot appeared by pressing one of two keys. The dot remained on screen until a response was made by the participant. The inter-trial interval varied randomly between $1500 \mathrm{~ms}$ and $3000 \mathrm{~ms}$ to prevent expectations of when the next trial would begin (see Fig. 1).

\subsection{Carbon monoxide monitor}

A carbon monoxide BreathCO monitor (Vitalograph, Lenexa, Kansas) was used to assess prior tobacco smoke exposure.

\subsection{Procedure}

Participants were asked to come to the lab for two test sessions which were scheduled on separate days. They were informed that Session 1 would consist of a behavioral task and a series of questionnaires, and that Session 2 would consist of another set of questionnaires about their daily habits. Participants were instructed to refrain from smoking for one hour before the first experimental session. This was necessary given that individual differences in nicotine craving can affect attention to smoking-related cues (Waters \& Feyerabend, 2000).

\subsection{Session 1}

The first session, which lasted approximately forty minutes, consisted of the dot-probe task, an approach/avoidance task, and electronically administered questionnaires. Participants completed this session in small groups of two to four students and were seated at private computer stations. All participants were seated $90 \mathrm{~cm}$ from the standardized position of a computer monitor, yielding a visual angle 236 of about 6 degrees. Participants were told that the purpose of the 237 study was to examine connections between attention and various vari- 238 ables. After completing a consent form, a carbon monoxide reading was 239 taken via a BreathCO monitor (Vitalograph, Lenexa KS) as a measure of 240 compliance (Field, Duka, Tyler, \& Schoenmakers, 2009). Participants 241 were then given instructions on how to complete the computer task 242 and were given a practice block of six trials to familiarize them with 243 the paradigm. Two experimental blocks of the dot-probe task were 244 then completed, separated by a short (25-30 second) break. Finally, 245 participants completed the Fagerstrom Test for Nicotine Dependence 246 (FTND) online.

\subsection{Session 2}

This session lasted approximately forty-five minutes and con- 249 sisted of a series of electronically-based questionnaires and inter- 250 views which included the demographic questionnaire, the general 251 smoking questionnaire, and the timeline follow-back procedure for 252 alcohol consumption. This session occurred within 2 weeks of the 253 first session. After the completion of these measures, participants 254 were debriefed, paid (if applicable), and thanked for their time. 255

\section{Results}

\subsection{Participant Characteristics}

Of the 70 participants recruited, nine were excluded from data anal- 258 ysis because they were older than 25 years $(n=1)$, failed to comply 259 with instructions to not smoke for one hour before the first testing ses- 260 sion $(n=1)$, or they did not return for the second day of testing $(n=7) .261$ Of the remaining 61 participants, 11 participants reported that they had 262 a smoking father, 8 had a smoking mother, and for 10 , both parents 263 smoked. These participants were all combined into one group 264 $(n=29)$. The remaining 32 participants reported that their parents 265 did not smoke during their lifetime. Participants were also categorized 266 according to their smoking frequency; that is, those who smoked at 267 least one cigarette per day were classified as daily smokers $(n=34), 268$ whereas those who did not smoke every day were classified as 269

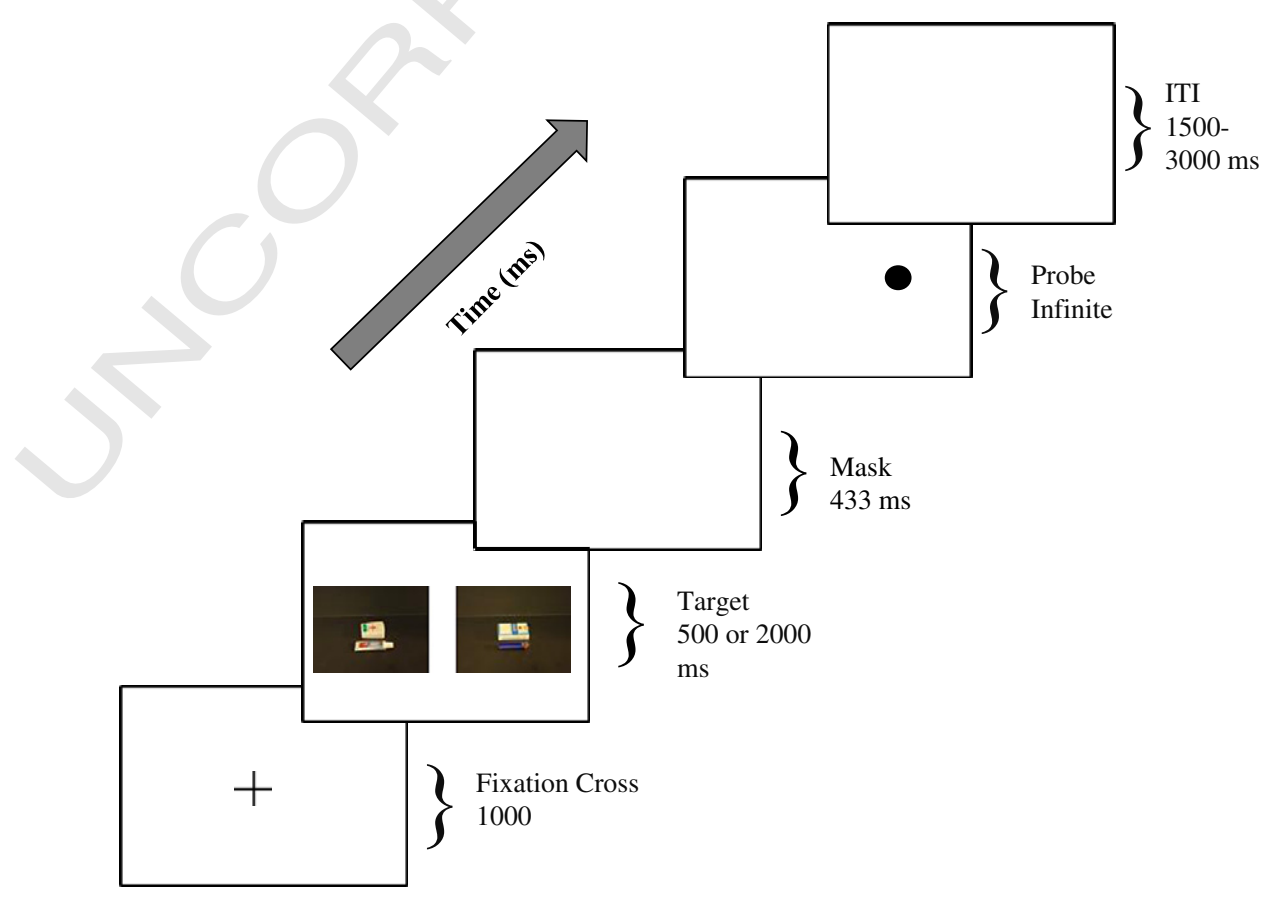

Fig. 1. A schematic of the dot-probe task. The screens were presented in chronological order. Duration is listed to the right of each screen. 
occasional smokers ( $n=27$; Hammond, 2005, Leatherdale \& McDonald, 2005).

Compared to occasional smokers, daily smokers had higher CO levels $(M=7.03, S E=1.15$ vs. $M=1.26, S E=0.20, F(1,56)=24.08$, $\left.p<.001, \eta^{2}=.30\right)$, reported smoking more cigarettes per week $(M=43.67, S E=5.76$ vs. $M=1.75, S E=0.23 ; \quad F(1,55)=37.92$, $\left.p<.001, \eta^{2}=.408\right)$, and had higher nicotine dependence scores on the FTND $(M=2.07, S E=0.26$ vs. $M=0.27, S E=0.10 ; F(1,55)=26.57$, $\left.p<.001, \eta^{2}=.334\right)$. However, there was no difference in the number of standard drinks they had consumed over the previous three weeks between these groups $(M=36.0, S E=5.25$ vs. $M=34.0, S E=6.90)$. There were no significant main effects of parental smoking status, nor did parental smoking status interact with participants' smoking status on any of these variables (all $p s>.33$ ).

\subsection{Measures of Attentional Bias}

Only reaction times (RTs) from correct trials, where participants accurately identified the location of the dot, were used in the analyses. To examine the relative attention to smoking compared to non-smoking cues, a difference score was calculated in which reaction times to trials in which the dot-probe appeared on the side of the smoking picture were subtracted from the reaction times to trials in which the dotprobe appeared on the side of the non-smoking picture for $500 \mathrm{~ms}$ and $2000 \mathrm{~ms}$ blocks. Initial analyses revealed that stimulus presentation time was not a significant predictor of attentional bias and did not interact with other variables; therefore this variable was not included in any of the subsequent analyses. Positive difference scores indicated greater attention to the smoking-related pictures relative to the non-smokingrelated pictures. Greenhouse-Geisser-adjusted $p$ values are reported for analyses involving multiple numerator degrees of freedom.

To test the hypothesis that attentional bias to smoking-related cues would differ based on the parents' smoking status and the properties of the stimuli for each group of smokers, a 2 (parent smoking status: neither vs. one or both parents smoke) x 2 (participant smoking status: occasional vs. daily) x 2 (stimulus category: active vs. inactive) mixedmodel analysis of covariance (ANCOVA) was conducted with attentional bias to smoking-related cues as a dependent measure. CO level was included as a covariate in the analyses to control for exposure to cigarette smoke, as was time spent with smokers over the past month to control for the influence of smoking peers. Results revealed the hypothesized stimulus category $\mathrm{x}$ participant smoking status $\mathrm{x}$ parental smoking status interaction, $F(1,52)=5.97, p<\theta .02, \eta^{2}=0.103$.

In order to further investigate this three-way interaction, parent smoking status x stimulus category ANCOVAs were conducted separately for daily and occasional smokers. While this analysis failed to reveal a significant interaction for occasional smokers ( $p>34$ ), for daily smokers, there was a parental smoking status $\mathrm{x}$ stimulus category interaction, $F(1,28)=7.60, p=.01, \eta^{2}=0.21$. As depicted in Fig. 2 , simple main effects analyses suggested that for the inactive cues, daily smokers who had a smoking parent displayed more of an attentional bias relative to daily smokers without a smoking parent, $F(1,28)=5.22$, $p=.03, \eta^{2}=0.16$. However, for the active stimuli, no differences between daily smokers with a smoking parent and those without a smoking parent emerged $(p>\theta .25)$.

Additional analyses were performed to determine whether nicotine dependence and parental smoking uniquely predicted attentional bias to the inactive smoking-related cues in daily smokers. Specifically, measures of nicotine dependence as measured by the FTND and the proportion of primary smoking relatives with whom the participant had contact were included as independent variables in a regression analysis. Results revealed that the proportion of smoking primary relatives was a significant predictor, $\beta=0.38, p<.05$, as was nicotine dependence (FTND), $\beta=0.32, p<.03$, with the overall model predicting a significant amount of the variance in attentional bias, $F(2,30)=7.03, p<.01, R^{2}=0.32$.

\section{Discussion}

The current study investigated how parental smoking interacts 335 with participants' smoking habits to influence attentional bias to 336 smoking-related cues. Results indicated that daily smokers who had 337 exposure to parents who smoked showed more of an attentional 338 bias to inactive smoking-related cues than those without parents 339 who smoked. Additionally, nicotine dependence independently pre- 340 dicted attentional biases to the smoking cues in daily smokers. 341

Consistent with our findings with non-smokers (Forestell et al., in 342 press), the presence of an attentional bias in the current study was 343 found only for cues that did not depict humans interacting with the 344 smoking stimuli. This result may have occurred because participants 345 were distracted by the human content in the active picture stimuli 346 (see Bentin et al., 1996). In contrast to the findings with daily smokers 347 in the current study and non-smokers in previous work (Forestell et 348 al., (mes), occasional smokers' attentional bias did not differ for either 349 the active or inactive stimuli as a function of parental smoking behavior. 350 Previous research with occasional smokers, often referred to as "chip- 351 pers," suggests that while some may progress to daily smoking, many 352 continue to smoke only occasionally throughout their lifetime without 353 becoming dependent on nicotine (e.g., Shiffman, 1989; Shiffman, Paty, 354 Gnys, Kassel, \& Elash, 1995). This may be related to the fact that occa- 355 sional smokers are motivated by environmental cues such as social situ- 356 ations and interactions with smoking peers (Otsuki et al., 2008; 357 Stromberg et al., 2007) rather than the physiological effects of nicotine. 358 Therefore, while occasional smokers may enjoy the acute effects of nic- 359 otine and may be motivated to smoke around other smokers in social 360 situations, because they do not have an attentional bias, they may not 361 be drawn to cigarette cues outside of these situations. Whether occa- 362 sional smokers who have stronger attentional biases to smoking- 363 related cues are more likely to progress to daily smoking is an important 364 topic of investigation which will require longitudinal studies. 365

Given that non-smokers in previous work and daily smokers in the 366 current study demonstrated the same pattern of attentional bias to 367 smoking-related cues, while non-addicted occasional smokers showed 368 no evidence of attentional bias, our results suggest that attentional 369 bias may not be a predictor for smoking initiation per se. Instead, 370 those who have attentional biases to smoking cues may be more vulner- 371 able to nicotine addiction once they have initiated smoking and as a re- 372 sult, may have an especially difficult time quitting smoking (e.g. Bradley 373 et al., 2003). Why some children of smokers who clearly demonstrate 374 attentional biases to smoking-related cues never engage in smoking be- 375 havior while others do is unknown. Clearly, early learning about tobac- 376 co and cigarette smoking is complex and involves many factors such as 377 frequency of exposure to family and peer smokers and parental atti- 378 tudes about smoking (Andersen et al., 2002).

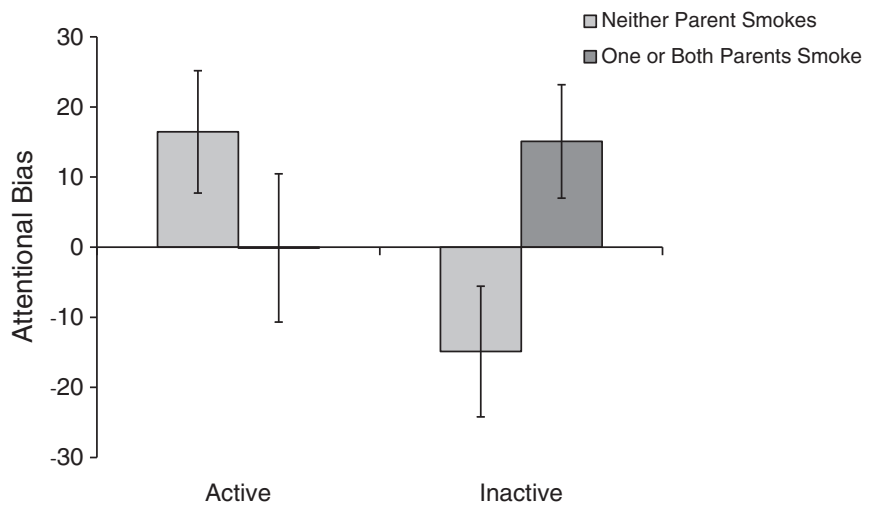

Fig. 2. Attentional bias in daily smokers as a function of cue type and parental smoking. Error bars represent standard errors. 
Previous work has also suggested that the context in which parents smoke may also play a role, as children whose mothers smoked cigarettes to relieve tension disliked the odor of cigarette smoke more than children whose mothers smoked for reasons other than relief from tension (Forestell \& Mennella, 2005). In other words, when children experienced odors during negative emotional situations, they were less likely to subsequently prefer them, suggesting that associative learning in the context of emotionally salient conditions is a powerful mechanism by which smoking-related cues acquire personal significance and influence subsequent behaviors. Because the current study was retrospective, it was impossible to determine whether the associations formed between smoking-related cues and the emotional contexts in which smoking occurs ultimately influence the attentional biases observed in the current sample of adults. Future research can address this by measuring attentional biases in young children who differ in terms of the emotional context in which their parents smoke. Although it is possible that exposure to smoking cues in the home causes these cues to become salient attractors of attention, research has also established a genetic link for smoking initiation and addiction (Heath et al., 1993). Therefore, children of smokers may also be genetically predisposed to attend to these stimuli. These two possibilities are not mutually exclusive and, regardless of the mechanism, the current results help inform models of drug addiction.

In addition to parental influence, dependence as measured by the FTND was also related to the strength of the attentional bias demonstrated in daily smokers. Theories of drug addiction suggest that attention to drug-related cues is important in the maintenance of drug use and the success of drug cessation attempts (e.g., Bradley et al., 2003; Robinson \& Berridge, 1993; Waters \& Feyerabend, 2000). As a result, most quit attempts by daily smokers are unsuccessful, with a success rate of less than $5 \%$ for smokers who try to quit on their own and less than $25 \%$ for those with professional help (Hughes et al., 1992; Ward, Klesges, Zbikowski Ryan, \& Susan, 1997). Our results suggest that attentional bias may help explain why relapses tend to occur within the first few days of quitting (Garvey, Bliss, Hitchcock, Heinold, \& Rosner, 1992; Hughes et al., 1992). However, it should be noted that the FTND is limited as a measure of nicotine dependence despite the extensive use of this scale and its predecessor (i.e., the Fagerström Tolerance Questionnaire; Fagerström \& Schneider, 1989). Over the past 25 years, its reliability and validity have been questioned (for a review see Piper, McCarthy, \& Baker, 2006) as measures of dependence. Instead, the FTND has been shown to be a better predictor of smoking heaviness and relapse rather than nicotine dependence per se (e.g., Alterman, Gariti, Cook, \& Cnaan, 1999; Breslau \& Johnson, 2000; Patten, Martin, Calfas, Lento, \& Wolter, 2001). In response to these drawbacks, new measures of tobacco dependence are being developed, but more research is required to establish construct validity. A better understanding of mechanisms underlying tobacco dependence and how it interacts with various theoretical and social factors such as those reported herein is warranted.

The investigation of smokers' and non-smokers' implicit biases to smoking-related cues could be instrumental in the development of evidence-based strategies for identifying at-risk individuals and cessation techniques. For example, the results of the current study and other recent work (Bradley et al., 2004; Haight \& Dickter, stbmitted for publication) imply that the presence of implicit biases, both attentional and affective, could impact the success of smoking cessation programs. As a result, these programs may benefit from taking these implicit biases into consideration in their design. Because implicit biases have been shown to be somewhat malleable (Dasgupta \& Greenwald, 2001), one strategy that may improve the success rate of daily smokers involves altering their implicit biases to smokingrelated stimuli. Implicit cognitive tasks may be used to train smokers with attentional biases to avoid attending to smoking-related stimuli. In fact, implicit training has been successfully implemented in substance-addicted individuals (Field et al., 2009; Schoenmakers et al., 2007), who showed lower instances of short-term and long- term drug use (Fadardi \& Cox, 2009). One potential implementation 446 Q16 of this could involve presenting participants with images depicting 447 negative smoking-related stimuli, such as those recently designed 448 by the Food and Drug Association to appear on packages of cigarettes 449 and smoking advertisements in the United States. Future research 450 should investigate whether exposure to these negative smoking im- 451 ages affects the implicit cognitive processing of smoking-related cues. 452

Another avenue for future work should involve investigating how 453 peer smoking behavior relates to attentional biases to smoking cues, 454 as previous work has suggested that peer smoking behavior plays a 455 key role in smoking initiation (e.g., Alexander, Piazza, Mekos, \& 456 Valente, 2001). Although it is possible that individuals who had 457 smoking parents were drawn to peers who smoke, which may have 458 mediated the strength of their attentional bias observed in this 459 study, our results suggest that their attentional bias was not merely 460 a function of peer smoking behavior. First, smokers with a smoking 461 parent did not differ from those without a smoking parent in time 462 spent with peers who smoke. Second, the results demonstrated an at- 463 tentional bias while controlling for time spent with smoking peers. 464 Together these findings suggest that parental smoking leads to an at- 465 tentional bias over and above the influence of smoking peers. It is 466 possible that peer influence may play a unique role in the acquisition 467 and maintenance of attentional biases, especially for early-onset ado- 468 lescent smokers.

The current study investigated how participants' smoking behavior 470 and their parents' smoking behavior interact to affect attentional biases 471 towards smoking-related cues. Results indicated that daily smokers 472 with a smoking parent demonstrate an attentional bias towards smok- 473 ing stimuli without human content. Importantly, these results were 474 found despite controlling for recent smoking behavior and time spent 475 with smokers. Results demonstrated that the higher participants' de- 476 pendence on nicotine and the more family members who smoke, the 477 greater the attentional bias. These findings help to explain why children 478 of smokers initiate and maintain smoking at higher levels than those 479 without a smoking parent and suggest that smokers who are addicted 480 to nicotine may have a particularly challenging time quitting, especially 481 if they were exposed to parental smoking throughout development. Fu- 482 ture research that examines the effects of parental smoking on children 483 through the use of psychophysiological measures, such as electroen- 484 cephalography, will provide further insight into the mechanisms in- 485 volved in the development of attentional biases to smoking-related 486 cues.

\section{Uncited references}

Cox et al., 2001

d' Alfonso, et al., 2000

Dasgupta and Asgari, 2004

Tiffany and Drobes, 1990

Cheryl L. Dickter and Catherine A. Forestell designed the study, conducted data 496 analysis, and wrote the manuscript together. Both authors have approved the final 497 manuscript.

\section{Conflict of Interest}

Both authors declare that they have no conflicts of interest. for their help with data collection. 


\section{References}

Alexander, C., Piazza, M., Mekos, D., \& Valente, T. W. (2001). Peer networks and adolescent cigarette smoking: An analysis of the national longitudinal study of adolescent health. Journal of School Health, 29, 22-30.

Alterman, A. I., Gariti, P., Cook, T. G., \& Cnaan, A. (1999). Nicodermal patch adherence and its correlates. Drug and Alcohol Dependence, 53, 159-165.

American Cancer Society (2009). Cancer Prevention \& Early Detection, Facts \& Figures 2009. Atlanta, GA: American Cancer Society.

Andersen, M. R., Leroux, B. G., Marek, P. M., Peterson, A. V., Jr., Kealey, K. A., Bricker, J., et al. (2002). Mothers' attitudes and concerns about their children smoking: Do they influence kids? Preventive Medicine: An International Journal Devoted to Practice and Theory, 34(2), 198-206.

Bauman, K. E., Foshee, V. A., Linzer, M. A. \& Koch, G. G. (1990). Effect of parental smoking classification on the association between parental and adolescent smoking. Addictive Behaviors, 15(5), 413-422.

Bentin, S., Allison, T., Puce, A., Perez, E., \& McCarthy, G. (1996). Electrophysiological studies of face perception in humans. Journal of Cognitive Neuroscience, 8(6), 551-565.

Bradley, B. P., Field, M., Mogg, K., \& Houwer, De (2004). Attentional and evaluative biases for smoking cues in nicotine dependence: Component processes of biases in visual orienting. Behavioral Pharmacology, 15, 29-36.

Bradley, B. P., Mogg, K., Wright, T., \& Field, M. (2003). Attentional bias in drug dependence: Vigilance for cigarette-related cues in smokers. Psychology of Addictive Behaviors, 17(1), 66-72.

Breslau, N., \& Johnson, E. O. (2000). Predicting smoking cessation and major depression in nicotine-dependent smokers. American Journal of Public Health, 90, 1122-1127.

Centers for Disease Control and Prevention (CDC) (2009). Cigarette smoking among adults and trends in smoking cessation - United States. Morbidity and Mortality Weekly Report, 58(44), 1227-1232.

Chassin, L., Presson, C. C., Pitts, S. C., \& Sherman, S. J. (2000). The natural history of cigarette smoking from adolescence to adulthood in a midwestern community sample: Multiple trajectories and their psychosocial correlates. Health Psychology, 19, 223-231.

Chassin, L., Presson, C., Rose, J., Sherman, S. J., \& Prost, J. (2002). Parental smoking cessation and adolescent smoking. Journal of Pediatric Psychology, 27(6), 485-496.

Chassin, L., Presson, C. C., Sherman, S. J., \& Pitts, S. C. (2000). The natural history of cigarette smoking from adolescence to adulthood in a 21 idwestern community sample: Multiple trajectories and their correlates. Health Psychology, 19, 223-231.

Chassin, L., Sherman, S. J., Presson, C. C., \& Edwards, D. (1991). Four pathways to youngadult smoking status: Adolescent social-psychological antecedents in a 21 idwestern community sample. Health Psychology, 10, 409-418.

Colder, C. R., Lloyd-Richardson, E. E., Flaherty, B. P., Hedeker, D., Segawa, E., \& Flay, B. R. (2006). The natural history of college smoking: Trajectories of daily smoking during the freshman year. Addictive Behaviors, 31, 2212-2222.

Cox, L. S., Tiffany, S. T., \& Christen, A. G. (2001). Evaluation of the brief questionnaire of smoking urges (OSU brief) in laboratory and clinical-settings. Nicotine E Tobacco Research, 3, 716 .

d' Alfonso,, A. A. L., van Honk, J., Hermans, E., Postma, A., \& de Haan, E. H. F. (2000) baterality effects in selective attention to threat after repetitive transcranial mag netic stimulation at the prefrontal cortex in female subjects. Neuroscience Letters, 280(3), 195-198, doi:10.1016/S0304-3940(00)00781-3.

Dasgupta, N., \& Asgari, S. (2004). Seeing is believing: Exposure to counterstereotypic women leaders and its effect on the malleability of automatic gender stereotyping. Journal of Experimental Social Psychology, 40,642-658.

Dasgupta, N., \& Greenwald, A. G. (2001). On the malleability of automatic attitudes: Combating automatic prejudice with images of admired and disliked individuals. Journal of Personality and Social Psychology, 81, 800-814.

Den Exter Blokland, E. A. W., Engels, R. C. M. E., Hale, W. W., III, Meeus, W., \& Willemsen, M. C. (2004). Lifetime parental smoking history and cessation and early adolescent smoking behavior. Preventive Medicine: An International Journal Devoted to Practice and Theory, 38, 359-368.

Etter, J. F., Duc, T. V., \& Perneger, T. V. (1999). Validity of the Fagerström test for nicotine dependence and the Heaviness of Smoking Index among relatively light smokers. Addiction, 94, 269-281.

European Environment and Health Information System (2007). Exposure of children to environmental tobacco smoke. May. http://www.euro.who.int/data/assets/pdf_file/ 0006/97422/3.4_WEB.pdf Retrieved from

Fagerström, K. O., \& Schneider, N. G. (1989). Measuring nicotine dependence: a review of the Fagerstrom Tolerance Questionnaire. Journal of Behavioral Medicine, 12, 159-182.

Field, Matt, Duka, T., Tyler, E., \& Schoenmakers, T. (2009). Attentional bias modification in tobacco smokers. Nicotine E Tobacco Research, 11, 812-822, doi:10.1093/ntr/ntp067.

Flay, B. R., Hu, F. B., Siddiqui, O., Day, L. E., Hedeker, D., Petraitis, J., Richardson, J., et al. (1994). Differential Influence of Parental Smoking and Friends' Smoking on Adolescent Initiation and Escalation and Smoking. Journal of Health and Social Behavior, 35(3), 248-265, doi:10.2307/2137279.

Forestell, C. A., \& Mennella, J. A. (2005). Children's hedonic judgments of cigarette smoke odor: Effects of parental smoking and maternal mood. Psychology of Addictive Behaviors, 19, 423-432.

Forestell, C. A., Dickter, C. L., Wright, J. D., \& Young, C. M. (in press). Clearing the smoke: Parental influences on non-smokers' attentional biases to smoking-related cues. Psychology of Addictive Behaviors.

Franken, I. H. A. (2003). Drug craving and addiction: integrating psychological and neuropsychopharmacological approaches. Progress in Neuro-Psychopharmacology and Biological Psychiatry, 27, 563-579.
Garvey, A. J., Bliss, R. E., Hitchcock, J. L., Heinold, J. W., \& Rosner, B. (1992). Predictors of 587 smoking relapse among self-quitters: A report from the normative aging study. Ad- 588 dictive Behaviors, 17, 367-377.

Haddock, C. K., Lando, H., Klesges, R. C., Talcott, G. W., \& Renaud, E. A. (1999). A study of 590 the psychometric and predictive properties of the Fagerström Test for Nicotine De- 591 pendence in a population of young smokers. Nicotine \& Tobacco Research, 1, 59-64. 592

Haight, J., Dickter, C. L., \& Forestell, C. A. A comparison of daily and occasional smokers' 593 implicit affective responses to smoking cues. 594 Q18

Hammond, D. (2005). Smoking behaviour among young adults: Beyond youth preven- 595 tion. Tobacco Control, 14, 181-185.

Heath, A. C., Cates, R., Martin, N. G., Meyer, J., Hewitt, J. K., Neale, M. C., \& Eaves, L. J. 597 (1993). Genetic contribution to risk of smoking initiation: Comparisons across 598 birth cohorts and across cultures. Journal of Substance Abuse, 5, 221-246. $\quad 599$

Hughes, J. R., Gulliver, S. B., Fenwick, J. W., Valliere, W. A., Cruser, K., Pepper, S., Shea, P., 600 et al. (1992). Smoking cessation among self-quitters. Health Psychology, 11, 331.601

Kleinjan, M., Engels, R. C. M. E., van Leeuwe, J., Brug, J., van Zundert, R. M. P., \& van den 602 Eijnden, R. J. J. M. (2009). Mechanisms of adolescent smoking cessation: Roles of 603 readiness to quit, nicotine dependence, and smoking of parents and peers. Drug 604 and alcohol dependence, 99, 204-214.

Leatherdale, S., \& McDonald, P. (2005). What smoking cessation approaches will young 606 smokers use? Addictive Behaviors, 30, 1614-1618. 607

McCusker, C. G. (2001). Cognitive biases and addiction: An evolution in theory and 608 method. Addiction, 96, 47-56.

Mennella, J. A., \& Forestell, C. A. (2008). Children's hedonic responses to the odors of 610 alcoholic beverages: A window to emotions. Alcohol, 42(4), 249-260. 611

Mogg, K., Bradley, B. P., Field, M., \& De Houwer, J. (2003). Eye movements to smoking- 612 related pictures in smokers: relationship between attentional biases and implicit 613 and explicit measures of stimulus valence. Addiction, 98, 825-836. 614

Moran, S., Wechsler, H., \& Rigotti, N. (2004). Social smoking among US college stu- 615 dents. Pediatrics, 114, 1028-1034.

Otsuki, M., Tinsley, B., Chao, R., \& Unger, J. (2008). An ecological perspective on smoking 617 among Asian American college students: The roles of social smoking and smoking 618 motives. Psychology of Addictive Behaviors, 22, 514-523. 619

Patten, C. A., Martin, J. E., Calfas, K. J., Lento, J., \& Wolter, T. D. (2001). Behavioral treat- 620 ment for smokers with a history of alcoholism: Predictors of successful outcome. 621 Journal of Consulting \&' Clinical Psychology., 69, 796-801.

Payne, T. J., Smith, P. O., McCracken, L. M., McSherry, W. C., \& Antony, M. M. (1994). 623 Assessing nicotine dependence: a comparison of the Fagerstrom Tolerance Ques- 624 tionnaire (FTQ) with the Fagerstrom Test for Nicotine Dependence (FTND) in a 625 clinical sample. Addictive Behaviors, 19, 307-317.

Piper, M. E., McCarthy, D. E., \& Baker, T. B. (2006). Assessing tobacco dependence: a guide 627 to measure evaluation and selection. Nicotine and Tobacco Research, 8, 339-351. 628

Pomerleau, C. S., Carton, S. M., Lutzke, M. L., Flessland, K. A., \& Pomerleau, O. F. (1994). 629 Reliability of the Fagerström Tolerance Questionnaire and the Fagerström Test for 630 Nicotine Dependence. Addictive Behaviors, 19, 33-39.

Rivara, F. P., Ebel, B. E., Garrison, M. M., Christakis, D. A., Wiehe, S. E., \& Levy, D. T. 632 (2004). Prevention of smoking-related deaths in the United States. American Jour- 633 nal of Preventive Medicine, 27, 118-125.

Robinson, T., \& Berridge, K. (1993). The neural basis of drug craving: An incentive- 635 sensitization theory of addiction. Brain Research Reviews, 18, 247-291. 636

Saules, K. K., Pomerleau, C. S., Snedecor, S. M., Mehringer, A. M., Shadle, M. B., Kurth, C., 637 \& Krahn, D. D. (2004). Relationship of onset of cigarette smoking during college to 638 alcohol use, dieting concerns, and depressed mood: Results from the Young 639 Women's Health Survey. Addictive Behaviors, 29, 893-899. 640

Sherman, S., Rose, J., Koch, K., Presson, C., \& Chassin, L. (2003). Implicit and explicit at- 641 titudes toward cigarette smoking: The effects of context and motivation. Journal of 642 Social and Clinical Psychology, 22, 13-39.

Shiffman, S. (1989). Tobacco "chippers"-individual differences in tobacco dependence. 644 Psychopharmacology, 97(4), 539-547.

Shiffman, S., Paty, J. A., Gnys, M., Kassel, J. D., \& Elash, C. (1995). Nicotine withdrawal in 646 chippers and regular smokers: Subjective and cognitive effects. Health Psychology, 647 14(4), 301.

Stritzke, W., Breiner, M., Curtin, J., \& Lang, A. (2004). Assessment of substance cue reac- 649 tivity: Advances in reliability, specificity, and validity. Psychology of Addictive Be- 650 haviors, 18, 148-159.

Stromberg, P., Nichter, M., \& Nichter, M. (2007). Taking play seriously: Low-level smoking 652 among college students. Culture, Medicine E Psychiatry, 31, 1-24. 653

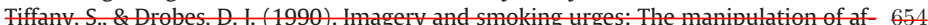
fective content. Addictive Behaviors, 15, 531539.

Ward, K. D., Klesges, R. C., Zbikowski Ryan, E., \& Susan, M. (1997). Gender differences in 656 the outcome of an unaided smoking cessation attempt. Addictive Behaviors, 22, 657 521-533.

Warren, C. A., \& McDonough, B. E. (1999). Event-related brain potentials as indicators 659 of smoking cue-reactivity. Clinical Neurophysiology, 110, 1570-1584. 660

Waters, A. J., \& Feyerabend, C. (2000). Determinants and effects of attentional bias in 661 smokers. Psychology of Addictive Behaviors, 14, 111-120.

Waters, A. J., Shiffman, S., Sayette, M. A., Paty, J. A., Gwaltney, C. J., \& Balabanis, M. H. 663 (2003). Attentional bias predicts outcome in smoking cessation. Health Psychology, 664 22, 378.

Williams, J. G. W., Mathews, A., \& MacLeod, C. (1996). The emotional Stroop task and 666 psychopathology. Psychological Bulletin, 120, 3-24. 